\title{
Research and evaluation of water quality in outdoor swimming pools
}

\author{
Joanna Wyczarska-Kokot ${ }^{1}$, Anna Lempart ${ }^{1, *}$, and Marta Marciniak $^{1}$ \\ ${ }^{1}$ Institiute of Water and Wastewater Technology, Silesian University of Technology, \\ ul. Konarskiego 18, 44-100 Gliwice, Poland
}

\begin{abstract}
The article presents the assessment of the quality of water in outdoor pools, based on the results of bacteriological and physicochemical tests and their comparison with the admissible values in this respect. The analyzes were carried out during two bathing seasons, in 2017 and 2018. The quality of water from sports, recreational and children's pools was analyzed, as well as water introduced into the pools from the circulation systems. The decisive role in the assessment of pool water quality is played by the results of microbiological tests and the assessment of the sanitary condition of the facility. In pool water and circulatory water samples, the number of indicator microorganisms (CFU) did not exceed the limit values. The problem was the very high levels of chloroform $(>0.03 \mathrm{mg} / \mathrm{L})$ and THM $(>0.1 \mathrm{mg} / \mathrm{L})$, lower than the required redox values $(750 \mathrm{mV})$ and nitrate content, increasing over the bathing season. Considering that the analyzed pools are seasonal and recreational outdoor pools, the observed excessive concentrations of DBP, with a short exposure, did not pose a direct threat to the health of bathers. However, they indicate the need to supervise the processes of water treatment and disinfection or their modernization.
\end{abstract}

\section{Introduction}

Public awareness of a healthy and active lifestyle translates, inter alia, into increased interest in water sports. Swimming is one of the most popular aquatic activities. Just like natural water, public pool water may contain microbiological and chemical contaminants. Possible sources of these contaminants in swimming pools include contamination from swimmers (saliva, sweat, cosmetics and urine), from the water supplied to the pool, from circulation, water treatment and disinfection system [1-5]. For outdoor pools, additional pollutants are creams, suntan oils and pollutants coming from leaves and dust in the surrounding environment or from rain water $[6,7]$.

Therefore, the quality of the water in pools, and thus the health safety of swimmers, will be influenced by (apart from the effectiveness of treatment): the way of swimming pool operation, cooperation of the hydraulic system with the treatment and disinfection system, the number of swimmers and their intensity of swimming (pool load) [3, 8-10].

\footnotetext{
* Corresponding author: anna.lempart@polsl.pl
} 
Both swimmers and staff of the swimming pool facilities may be exposed to contamination by accidental ingestion of water, inhalation of water aerosols and absorption through skin [11-15].

Lack of proper quality control of the pool water can result in health risks for swimmers and staff and the spread of infections. For the above reasons, ensuring the safety of pool users is a priority. For this purpose, documents regulating the admissible values of physicochemical and microbiological parameters of swimming pool water were issued. The most important document in most countries is the regulation in force. In Poland, it is the Ministry of Health's regulation of 2016, on the requirements of water in swimming pools [16]. A more detailed one is a German norm, a European-like standard which also specifies methods for treating swimming pool water [17]. The general guidelines on the basis of which legal regulations were created in individual countries are specified in the document of the World Health Organization [18]. It should be emphasized that the quality of water in both outdoor and indoor swimming pools is subject to legal regulations.

The aim of this work is to assess the quality of water in outdoor pools, during the entire bathing season, based on the results of bacteriological and physicochemical tests and their comparison with the admissible values.

\section{Characteristics of research objects}

The tested facility includes: recreational swimming pool (RP), children's pool (CP), sports swimming pool (SP) and a water playground. The facility has two closed circulations of water treatment: circuit I for the basin of a sports swimming pool (SP) and a water playground, and circuit II for a recreational pool (RP) and a pool for children (CP). The circuits are equipped with retention tanks with a capacity of $30 \mathrm{~m}^{3}$, and the filtration systems. The water was filtered with the help of the open vacuum washed with diatomaceous earth filters. The filters were rinsed every 3 days. In order to increase the filtration efficiency, a coagulant $(0.5 \%$ aluminum hydroxychloride solution) was added before the filters. The water disinfection was carried out with $13 \%$ sodium hypochlorite solution. If the $\mathrm{pH}$ of the water needed adjustment, a $30 \%$ solution of sulfuric acid was used. In order to prevent algal blooms, an algicide was periodically added. The basic technical parameters for the tested pools are summarized in Table 1.

Table 1. Technical parameters of the tested swimming pools.

\begin{tabular}{|c|c|c|c|c|c|}
\hline \multirow{2}{*}{ Parameter } & \multirow{2}{*}{ Unit } & \multicolumn{2}{|c|}{ Circuit I } & \multicolumn{2}{c|}{ Circuit II } \\
\cline { 3 - 6 } & & $\begin{array}{c}\text { Sport pool } \\
\text { (SP) }\end{array}$ & $\begin{array}{c}\text { Water } \\
\text { playground }\end{array}$ & $\begin{array}{c}\text { Recreation } \\
\text { al pool (RP) }\end{array}$ & $\begin{array}{c}\text { Children } \\
\text { pool (CP) }\end{array}$ \\
\hline $\begin{array}{c}\text { Dimensions of } \\
\text { the pool basin }\end{array}$ & $\mathrm{m} \times \mathrm{m}$ & $24.95 \times 12.37$ & $24.9 \times 20.8$ & $24.35 \times 12.2$ & $24.9 \times 20.8$ \\
\hline $\begin{array}{c}\text { Depth of the } \\
\text { pool basin }\end{array}$ & $\mathrm{m}$ & 1.2 & 0.0 & $0.8-1.2$ & $0.1-0.6$ \\
\hline Usable area & $\mathrm{m}^{2}$ & 285 & 90 & 268 & 420 \\
\hline $\begin{array}{c}\text { Volume of the } \\
\text { pool basin }\end{array}$ & $\mathrm{m}^{3}$ & 342 & 0.0 & 268 & 147 \\
\hline Max. attendance & $\mathrm{person} / \mathrm{h}$ & 68 & 30 & 72 & 80 \\
\hline $\begin{array}{c}\text { The time of one } \\
\text { water change in } \\
\text { the pool basin }\end{array}$ & $\mathrm{h}$ & 2.70 & 0.43 & 1.54 & 0.50 \\
\hline Filtration flow & $\mathrm{m}^{3} / \mathrm{h}$ & \multicolumn{2}{|c|}{190} & & 470 \\
\hline
\end{tabular}




\section{Materials and research methodology}

In order to assess the water quality in the tested outdoor swimming pools, the following parameters were analyzed: nitrate content (spectrophotometric method; spectrophotometer DR 3900 with RFID technology, Hach $\left.{ }^{\circledR}\right)$, free chlorine and combined chlorine (colorimetric method in situ, Pocket ColorimeterTM II, Hach ${ }^{\circledR}$ ), chloroform and total trihalomethane - THM (gas chromatography method, Agilent Technologies GC7890B chromatograph with MSD5977A mass detector), turbidity (nephelometric method, TN 100 turbidity meter, Eutech ${ }^{\circledR}$ ), the $\mathrm{pH}$ of water, redox and temperature (potentiometric method, sensION meter + MM150 DL, Hach ${ }^{\circledR}$ ), oxidisability - COD (titrimetric method in an acid environment in accordance with PN-EN ISO 8467:2001), number of colony forming units (CFU) Pseudomonas aeruginosa (method according to PN-EN ISO 16266:2009), the Escherichia coli CFU number (method according to PN-EN ISO 9308-1:2014-12/A1:201704) and the Legionella sp. CFU number (method according to PN-EN ISO 11731:2017).

Sampling took place in accordance with the guidelines of the Polish standard PN-ISO 5667-5:2003. Water samples were taken from swimming pools (SP, CP, RP) and test cocks were installed on pipelines of circuits I and II (SC1, SC2), supplying treated water to swimming pools. Samples were taken from a depth of about $30 \mathrm{~cm}$ below the water surface. During the bathing season in 2017, samples were taken 7 times ( 7 measuring days), and in 2018 six times (6 measurement days), taking into account the beginning and the end of the bathing season. The authors, guided by the experiments from previous studies, took samples at several characteristic basin points and used a mixed sample for analysis [8].

The results of the analysis were compared with the guidelines included in the documents specifying the requirements for water in swimming pools [16-18].

\section{Results and discussion}

The pool water $\mathrm{pH}$ values should be in the range of 6.5 to 7.6 , which is very important from the point of view of the efficiency and speed of disinfection, coagulation and the creation of disinfection by-products $[19,20]$. In the analyzed samples, the $\mathrm{pH}$ of the water did not differ from the recommended values and ranged from 6.90 to 7.60 . The average $\mathrm{pH}$ values of water in the following sampling points were: 7.22 in SC1, 7.32 in SC2, 7.26 in CP, 7.33 in $\mathrm{RP}$ and 7.30 in SP. There were no significant differences between the water $\mathrm{pH}$ values depending on the type of swimming pool (for children, recreational or sports) or water treatment system (circuit I, circuit II).

The redox potential values of water in pool basins at $\mathrm{pH}$ values between 6.5 and 7.3 should not be less than $750 \mathrm{mV}$, and at $\mathrm{pH}$ values between 7.3 and 7.6 not less than $770 \mathrm{mV}[16,17]$. In the analyzed water samples, both in the 2017 and 2018 bathing season, the redox values met the above requirement in only 3 out of 66 samples. The average redox values in the 2017 season were from $669 \mathrm{mV}$ (SC2) to $715 \mathrm{mV}$ (SC1), and in the season 2018 from $671 \mathrm{mV}(\mathrm{CP})$ to $701 \mathrm{mV}$ (SP). Similarly as in the case of measuring the $\mathrm{pH}$ of water, no significant differences were found between the redox values depending on the type of pool or water treatment system. From the experience of authors and literature data $[9,13,20]$ it appears that maintaining high redox values, especially in open basins, requires supporting $\mathrm{NaOCl}$ disinfection with, for example, chlorine dioxide and/or ozone.

The turbidity of water entering the basin trough the circulation system should not be higher than $0.3 \mathrm{NTU}$, and the water in the basin should not be higher than 0.5 NTU [16, 17]. In the 2017 bathing season, this requirement was met in all samples. In the season 2018 in samples of water collected in the peak season (2-23.08.2018), during hot weather and maximum attendance, the turbidity of water entering the SP pool was $0.48 \mathrm{NTU}$, and the one in the basin $0.52 \mathrm{NTU}$. The turbidity of water introduced into the CP and RP basin was 
$0.63 \mathrm{NTU}$, and in the basins 1.30 and $0.98 \mathrm{NTU}$, respectively. To reduce such high turbidity values, the filter rinsing process was intensified in the following days. The filtration cycle was shortened from 3 to 2 days, thus obtaining water turbidity at the level of 0.15 NTU to 0.21 NTU.

Recommended concentrations of free chlorine in open water and with hydromassage devices should be from 0.7 to $1.0 \mathrm{mg} \mathrm{Cl}_{2} / \mathrm{L}$. There is no recommendation for water entering the basin trough the circulation system [16-18]. Both in the 2017 and 2018 bathing season, free chlorine concentrations were in accordance with the guidelines. In the 2017 season, free chlorine concentrations in $\mathrm{CP}$ pool were $0.70-0.96 \mathrm{mg} \mathrm{Cl} / \mathrm{L}$, in $\mathrm{RP}$ pool 0.40-0.89 $\mathrm{mg} \mathrm{Cl}_{2} / \mathrm{L}$, in SP pool $0.60-1.99 \mathrm{mg} \mathrm{Cl}_{2} / \mathrm{L}$. In the 2018 season, free chlorine concentrations in CP pool were $0.72-0.95 \mathrm{mg} \mathrm{Cl}_{2} / \mathrm{L}$, in $\mathrm{RP}$ pool $0.50-0.95 \mathrm{mgCl}_{2} / \mathrm{L}$, in SP pool $0.58-0.99 \mathrm{mg} \mathrm{Cl} / \mathrm{L}$. Constant dosing of stabilized sodium hypochlorite and measurement, and control of free chlorine concentration ensured its constant level in particular basins.

The concentrations of combined chlorine in the tested samples were very small and, with the exception of water samples collected on 3.08.2017, did not exceed the recommended values (Fig. 1). This was not the case with chloroform content (Fig. 2). In 25 samples tested in 2017, in as many as 22 the chloroform content significantly exceeded $0.03 \mathrm{mg} / \mathrm{L}$ (from 0.036 to $0.150 \mathrm{mg} / \mathrm{L}$ ). In 2018, in 19 out of 30 samples the chloroform content was above the limit value (from 0.032 to $0.110 \mathrm{mg} / \mathrm{L}$ ). The presence of too high chloroform content was also reflected in the excess THM content (Fig. 3). High levels of DBP may indicate irregularities in the water treatment process, especially in the process of its disinfection. It is necessary to check the water disinfection phases, change or improve the applied technologies, e.g. apply an additional oxidizing agent.

In the analyzed pool waters, special attention was also paid to the content of nitrates. In the tests carried out at the beginning of the 2017 and 2018 season, the nitrate content ranged from 0.89 to $2.40 \mathrm{mg} \mathrm{NO}_{3}^{-} / \mathrm{L}$. It systematically increased and at the end of the seasons ranged from 10.00 to $19.00 \mathrm{mg} \mathrm{NO}_{3}^{-} / \mathrm{L}$, with a permissible content of $20.00 \mathrm{mg} \mathrm{NO}_{3}^{-} / \mathrm{L}$ (Fig. 4). High nitrate content in the pool water indicates insufficient exchange of circulating water for fresh make-up water (usually from the water supply network) and the potential for creating DBP.

a)

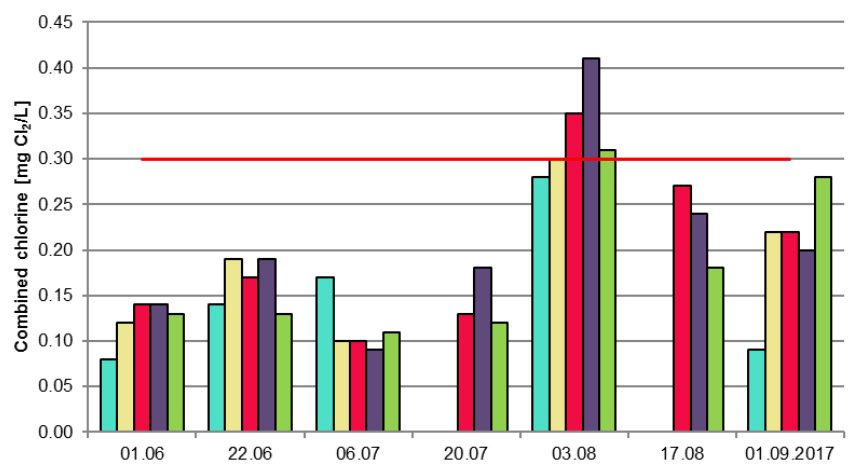


b)

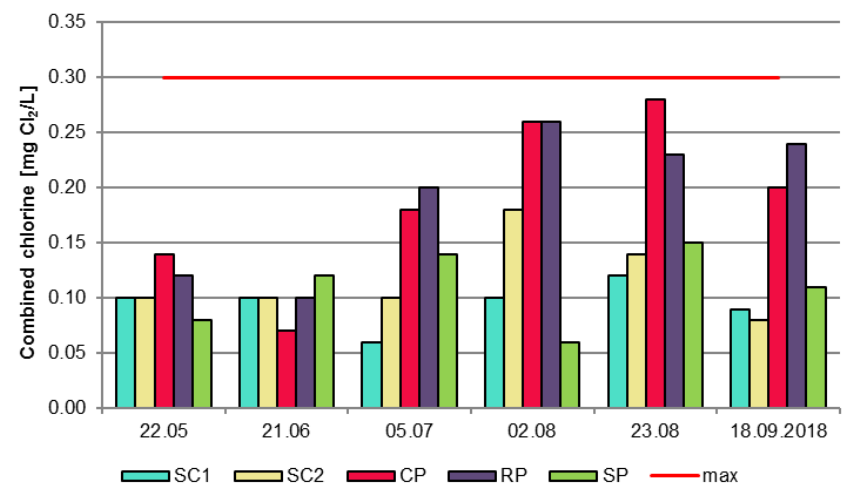

Fig. 1. Combined chlorine in tested swimming pool waters a) in 2017, b) in 2018.

a)

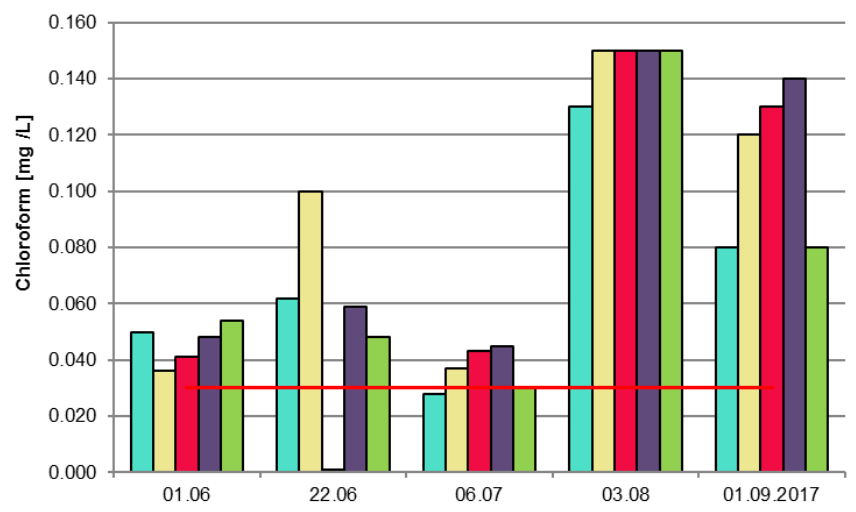

b)

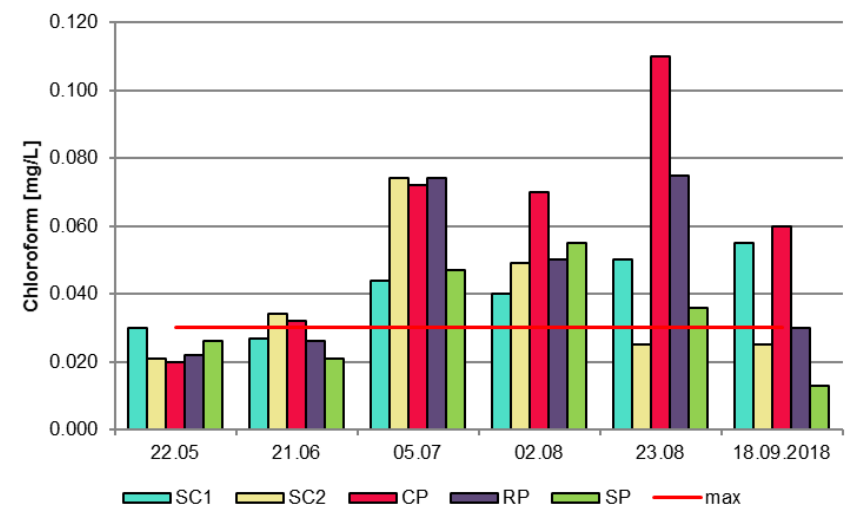

Fig. 2. Chloroform in tested swimming pool waters a) in 2017, b) in 2018. 
a)

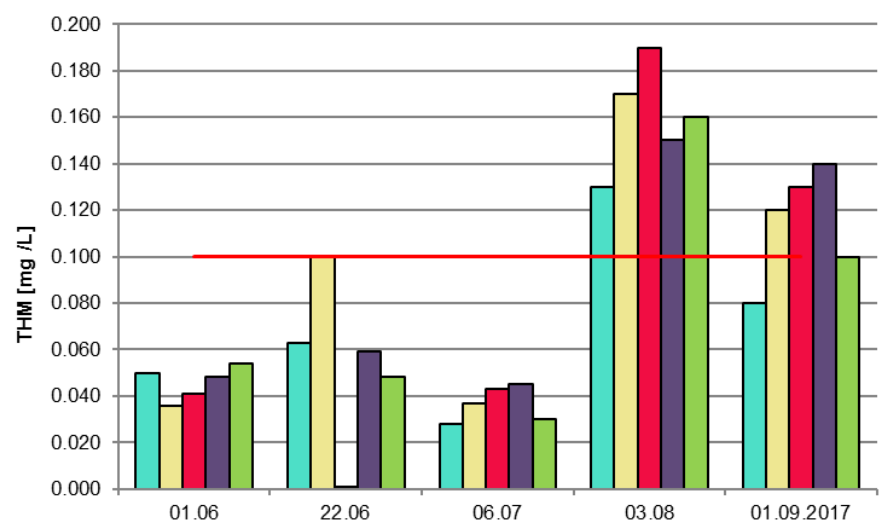

b)

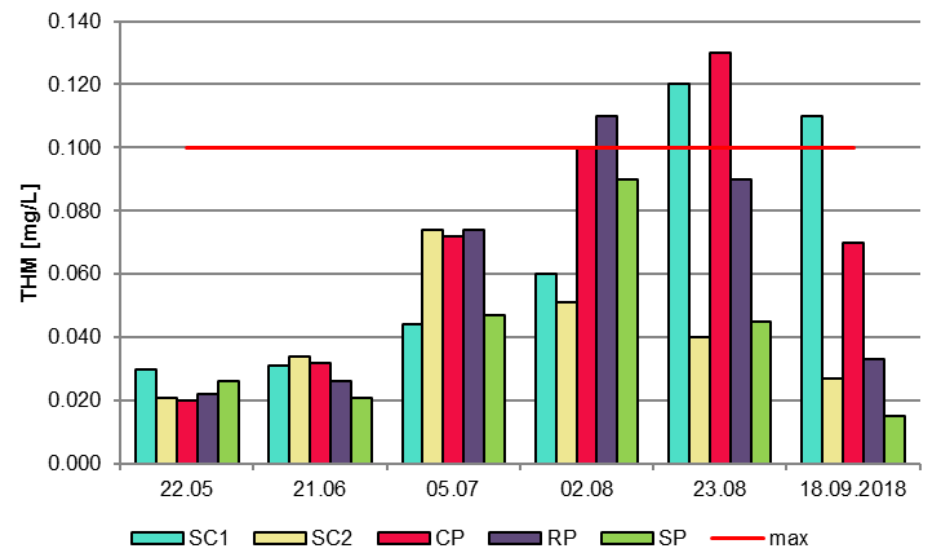

Fig. 3. THM in tested swimming pool waters a) in 2017, b) in 2018.

a)

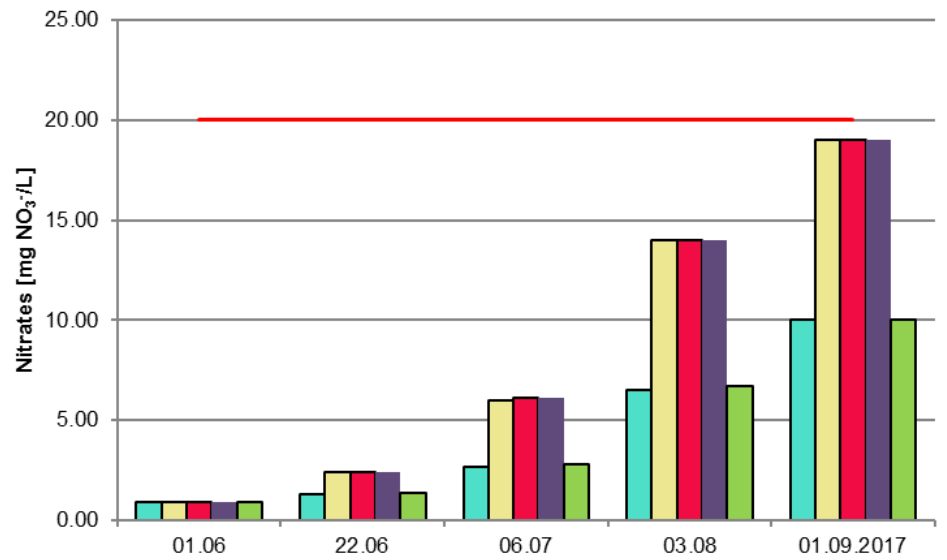


b)

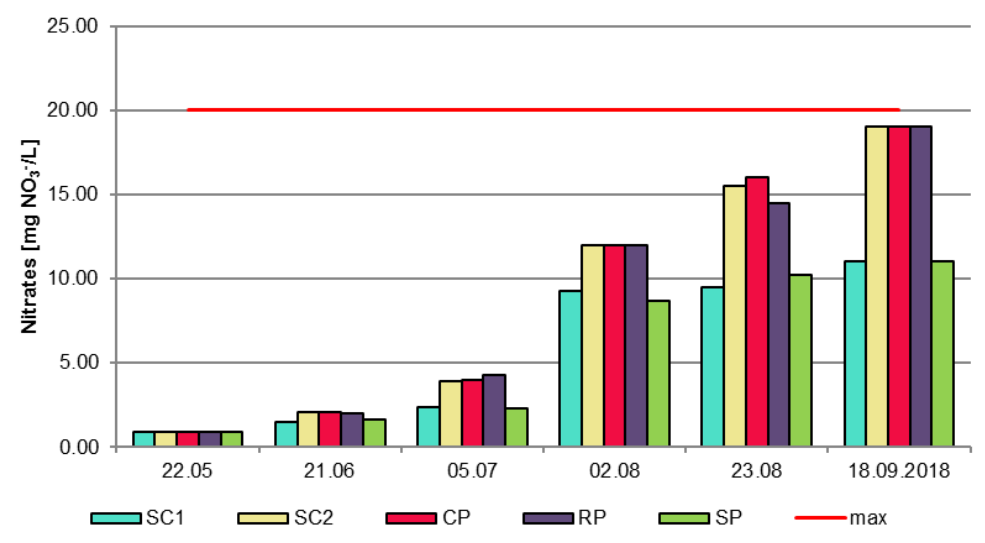

Fig. 4. Nitrates in tested swimming pool waters a) in 2017, b) in 2018.

\section{Conclusions}

The quality of pool water depends on various factors, such as the concentration of water pollutions and their volatility, the number of bathers and their behaviour, the ventilation system, the water and air temperature and the water circulation system.

The results of physicochemical tests of pool water quality parameters, carried out by sanitary inspection bodies, are treated as an auxiliary in assessing the degree of its contamination.

The decisive role is played by the results of microbiological tests and the assessment of the sanitary condition of the facility.

In the test cycle in 2017 and 2018, in the pool water samples (CP, RP, SP) and in the water samples from the circulation system (SC1, SC2), no CFU of Escherichia coli, Pseudomonas aeruginosa and Legionella $s p$. were found, and the total number of microorganisms in $36^{\circ} \mathrm{C}$ after 48 hours did not exceed $100 \mathrm{CFU} / 1 \mathrm{~mL}$ in pool water samples and $20 \mathrm{CFU} / 1 \mathrm{~mL}$ in the water samples from the circulation system.

Considering that the analyzed pools are seasonal and recreational outdoor swimming pools, the observed excessive values of disinfection by-products (DBP), i.e. chloroform and THM at short exposure, did not pose a direct threat to the health of bathers. However, they indicate the need to supervise the processes of water treatment and disinfection or their modernization. In such cases, the most common recommendation is to use at least two-stage disinfection of circulating water (irradiation with UV/ozonizing/dosing chlorine dioxide+dosing with $\mathrm{NaOCl}$ ) or using additional filtration through a bed of active carbon.

It needs to be remembered that testing swimming pool water quality for the content of DBP should be connected not only with the control of free chlorine, but also with redox potential and nitrogen content.

This work was supported by the Ministry of Science and Higher Education of the Republic of Poland within statutory funds and within funds for young scientists BKM-508/RIE-4/2018 awarded to the Institute of Water and Wastewater Engineering Silesian University of Technology in 2018.

\section{References}

1. T. L. L. Teo, H. M. Coleman, S. J. Khan, Environ. Int. 76, 16-31 (2015) 
2. M. M. A. El-Salam, Environ. Monit. Assess. 184, 7395-7406 (2012)

3. R. Tardif, M. Rodriguez, C. Catto, G. Charest-Tardif, S. Simard, J. Environ. Sci. 58, 163-172 (2017)

4. J. De Laat, W. Feng, D. A. Freyfer, F. Dossier-Berne, Water Res. 45, 1139-1146 (2011)

5. Q. Zheng, L. K. Jmaiff Blackstock, W. Deng, H. Wang, X. C. Le, X. F Li, J. Environ. Sci. 53, 322-325 (2017)

6. F. Yang, Z. Yang, H. Li, F. Jia, Y. Yang, Environ. Sci. Water Res. Technol. 4, 218-225 (2018)

7. W. L. Bradford, Int. J. Aquat. Res. Educ. 8, 168-181 (2014)

8. J. Wyczarska-Kokot, A. Lempart, M. Dudziak, Ecol. Chem. Eng. A. 24, 217-226 (2017)

9. H. Ilyas, I. Masih, J. van der Hoek, Water, 10, 797 (2018)

10. J. H. Jacobs, S. Spaan, G. B. G. J. van Rooy, C. Meliefste, V. A. C. Zaat, J. M. Rooyackers, D. Heederik, Eur. Respir. J. 29, 690-698 (2007)

11. T. Manasfi, B. Coulomb, J. L. Boudenne, Int. J. Hyg. Environ. Health. 220, 591-603 (2017)

12. C. M. Villanueva, S. Cordier, L. Font-Ribera, L. A. Salas, P. Levallois, Curr. Environ. Health Rpt. 2, 107-115 (2015)

13. M. Z. Afifi, E. R. Blatchley, Water Res. 68, 771-783 (2015)

14. A. Gomà, R. de Lluis, J. Roca-Ferrer, J. Lafuente, C. Picado, Environ. Res. 152, 315-321 (2017)

15. S. Simard, R. Tardif, M. J. Rodriguez, Water Res. 47, 1763-1772 (2013)

16. Polish Ordinance of the Minister of Health, Official Journal 2015, item. 2016 (2015)

17. DIN 19643, Water Treatment for Swimming and Bathing Pools (2012)

18. Guidelines for Safe Recreational Water Environments. Vol. 2: Swimming Pools and Similar Environments, WHO (2006)

19. K. M. S. Hansen, S. Willach, M. G. Antoniou, H. Mosbæk, H. J. Albrechtsen, H. R. Andersen, Water Res. 46, 6399-6409 (2012)

20. J. Wyczarska-Kokot, Desalin. Water Treat. 134, 7-14 (2018) 